\title{
MEMOIR
}

\section{ANTONIO THOMAS TRAVERSI}

Antonio Thomas Traversi, who died on 20 April 196r after a long illness, was born at Ross on the West Coast of the South Island of New Zealand on 22 November I 87 I. Educational facilities on the gold coast of the Dominion were not of the highest in those days, and at the time of his joining the Public Service in Wellington he lacked the benefit of a secondary education. In consequence, when he decided to sit for the examinations of the Institute of Actuaries he was hampered by the fact that he had no knowledge of algebra or any other branch of higher mathematics and had laboriously to acquire this knowledge by private study.

In 1906 he was appointed Actuary to the Friendly Societies and National Provident Fund Departments. At that time Friendly Societies in New Zealand were very strong numerically, but in general unsound financially. Although the legislation required quinquennial valuations of each Society or Branch, there was no direct provision to oblige the Societies to take steps towards solvency. It is a tribute to Mr Traversi's firmness and patience that during the ten years he occupied the position, great progress was made by many of the Societies towards solvency, and the writer, who occupied this position from 1921 to 1936 , had the satisfaction of seeing every Society reach full solvency.

In I9I7, Mr Traversi transferred to the Government Insurance Office of New Zealand as Assistant Actuary, becoming Actuary in 1922 and Commissioner in 1923 , retiring from that position in 1926.

After his retirement, Mr Traversi settled in Australia and built up an extensive private practice, specializing in Court evidence in Compensation cases and valuations of Company Superannuation Funds. During this period he contributed many papers to the Actuarial Society of Australasia and became its President in I93I. His Presidential Address dealt with the Economic Crisis and was mentioned in the Transactions of the Actuarial Society of America as a 'notable discussion of the subject'.

The writer was closely associated with Mr Traversi during the five years preceding his retirement from the Government Insurance Office of New Zealand and is able to speak of him not only as an actuary and assurance administrator of rare qualifications and endowments but as a scholar of great versatility, his interests ranging from music to philosophy and metaphysics. From his father, a native of one of the Italian cantons of Switzerland, he inherited his musical talents, being a proficient pianist, violinist and cornettist, as well as a conductor. I recall his pointing out that just as music and other branches of art have a mathematical basis, so mathematics has beauty, elegance and rhythm of its own.

With his frail physique, combined with a marked degree of deafness, and separated from his family, he must have been a lonely figure during his early years in Wellington, and it is not surprising that much of his spare time was devoted to general reading covering a wide range of subjects.

$\mathrm{He}$ was particularly interested in the history of all countries, and in their languages. He could speak French and Italian fluently, could read Spanish and Portuguese and had more than a passing acquaintance with Roumanian.

Though always studiously inclined, and from habit a daily reader, $\mathrm{Mr}$ Traversi maintained his breadth of vision by the diversity of his subjects and remained mentally alert and fully occupied in his profession till well into his eighties.

C. GOSTELOW 